\title{
Sometimes conventional removable partial denture is the only remedy!
}

Charfi Nihel ${ }^{1}$, Ouni Imed ${ }^{2}$, Mansour Lamia ${ }^{3}$, Trabelsi Mounir ${ }^{4}$

${ }^{1}$ Resident, Department of Removable Partial Prosthodontics, University Dental Clinic, Monastir, Tunisia.

${ }^{2}$ Associate Professor, Department of Removable Partial Prosthodontics, Faculty of Dental Medicine of Monastir, Monastir, Tunisia.

${ }^{3} \mathrm{DDS}, \mathrm{PhD}$, Prosthetic Department, Dental Clinic of Monastir, University of Monastir, , Avicenna Avenue, 5019 Monastir, Tunisia.

${ }^{4}$ DDS, PhD, Head of service, Prosthetic Department, Dental Clinic of Monastir, University of Monastir, Avicenna Avenue, 5019 Monastir, Tunisia.

\begin{abstract}
Management of partially edentulous patients can still be a prosthodontic challenge especially for extensive maxillary Kennedy Class I. Replacing the missing teeth using conventional fixed and removable partial dentures (FPD/RPDs) associated with extracoronal attachments remains sometimes the only remedy for partial edentulism. The use of osseointegrated dental implants turn the possibilities of prosthetic reconstruction endless, but what about patients with absolute contraindication of surgery. It is therefore the objective of this article to describe the treatment sequence and technique for the use of attachments in therapy combining FPD/RPD.
\end{abstract}

Key words: Extracoronal precision attachments; fixed partial denture; removable partial denture.

\section{Introduction}

$\mathrm{W}$

hen the use of conventional fixed partial dentures(FPDs) and/or dental implants is limited or not indicated, association between FPD and removable partial denture (RPD) by means of attachments becomes an important alternative to a conventional clasp-retained RPD. ${ }^{1,2}$

These retainers have been recommended as an alternative for abutment teeth of RPD, permitting the placement of rests and retentive clasps on the anterior teeth at sites that do not interfere with aesthetic appearance, thus making rehabilitation more acceptable to patients. ${ }^{3,4}$

Conflict of Interest: No

*Corresponding Author
Charfi Nihel, Resident
Department of Removable Partial Prosthodontics,
University Dental Clinic, Monastir, Tunisia.
E-mail: charfinihel@outlook.fr

\section{*Corresponding Author}

Charfi Nihel, Resident

University Dental Clinic, Monastir, Tunisia.

E-mail:charfinihel@outlook.fr 
clinic of Monastir-Tunisia, for esthetic and functional rehabilitation. Questionnaire reported compromised medical condition that prevents the ability to have any surgical procedures.

Figure 1 shows an extensive maxillary Kennedy Class I with only remaining four anterior teeth. Clinical and radiographic (Figure 2) examinations revealed severely resorbed alveolar ridges, a lack of posterior support, an evident loss of occlusal vertical dimension (OVD), and alteration in the occlusal plane.

After analysis of the diagnostic casts mounted on a semi adjustable articulator (Figure 3), treatment planning consisted of a maxillary rehabilitation by means of an association between tooth-supported FPD (from maxillary left canine to right central incisor) and RPD with attachments. (Figure 4)

This therapeutic modality was selected for those reasons:

- The large prosthetic space and the patient's maxillary bone width and height condition, which would require bone grafts, and that is already difficult especially for medical condition.

- Severely resorbed alveolar ridges that hinder the ability to place implants for an implant retained RPD and that require a resin flange to provide adequate support for facial structures.

- Compromised remaining teeth that cannot be used as abutments for traditional RPDs, and must be splinted for better resistance

After Endodontic treatment of the remaining teeth, the maxillary anterior teeth were prepared in accordance with biomechanical and esthetic principles. ${ }^{7,8}$ The maxillomandibular relationship, including reestablishment of the curves of Spee and Wilson and the OVD, was recorded with occlusion rims and an acrylic resin template, according to the metric, phonetic, and esthetic methods (Figure 5). The maxillary cast was oriented on the semi adjustable articulator with a facebow record and the mandibular cast was mounted.

The maxillary cast was surveyed in a dental surveyor to determine the most suitable path of insertion and removal. After that, the wax up of the maxillary anterior teeth were done with a cantilever right lateral incisor. The lingual surfaces were flattened to guide the insertion/ removal path of the RPD. A stress breaking extra coronal precision attachment (OT Cap, Rhein 83) with a vertical freedom of movement and an activation portion were fixed parallel to the path of insertion using a mandrel on the distal surface of the maxillary right lateral incisor and left canine.

The attachment was placed slightly palatal relative to the axis of the alveolar ridge; this position subsequently facilitates the assembly of artificial teeth. (Figure $6 \& 7$ )

After checking the vertical prosthetic space, the wax patterns were casted with nickel-chromium alloy. (Figure 8 \& 9)

The RPD framework was cast in a cobaltchromium alloy and clinically tried to check seating. The artificial teeth were selected and positioned. After deflasking, the RPD was finished and polished and the metal-ceramic FPD was glazed.

To ensure adequate seating during FPD cementation, the prostheses were attached extraorally (Figure 10), and glass ionomer cement was used. This procedure must be carried out when attachments are used for the association of an FPD/RPD, because a minimal error during FPD cementation may compromise the oral rehabilitation. 


\section{Results}

After polymerization, excess cement was removed, occlusal adjustment was performed, and the patient was instructed not to remove the RPD for 24 hours. On the next day, the overcompression of tissue was eliminated, and the occlusal adjustment was refined. The result achieved(Figure 11) indicates that both treatment planning and the treatment implemented were adequate. The patient received hygiene and care instructions.

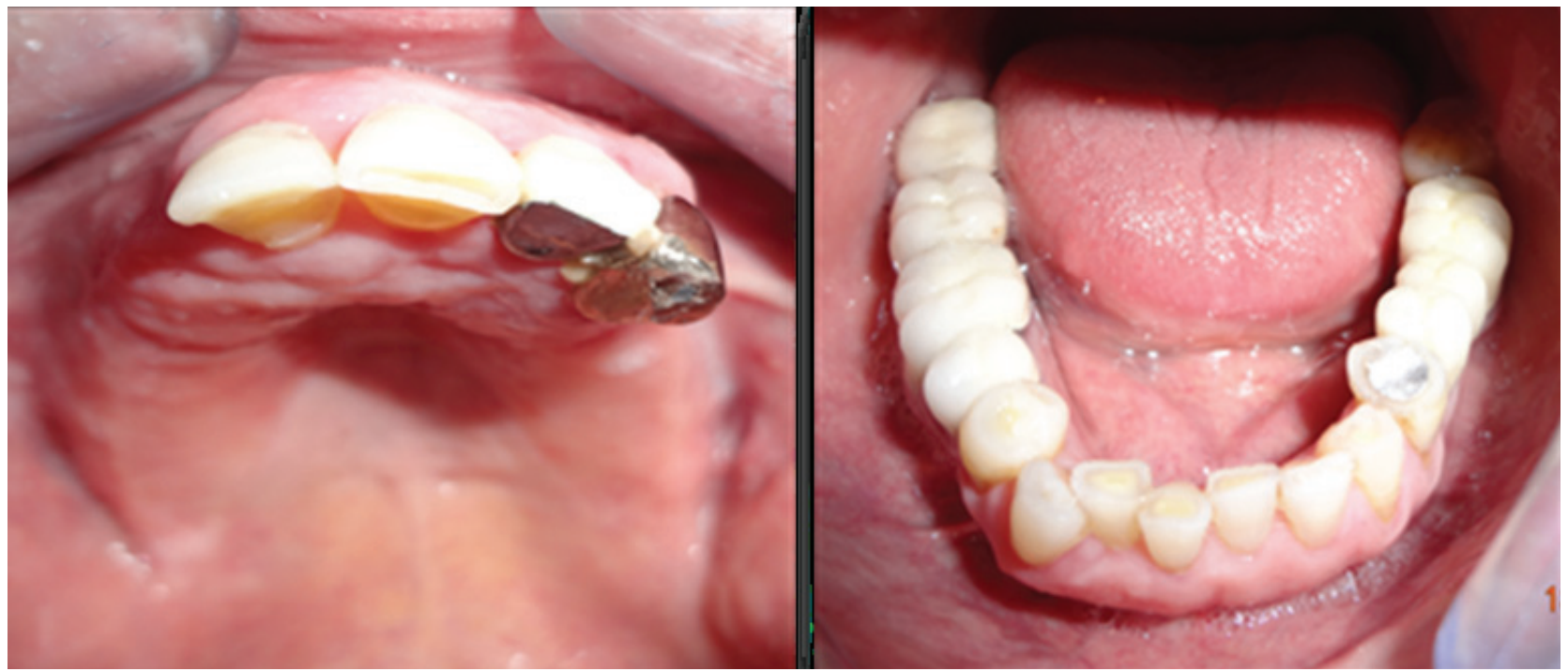

Figure 1: Pretreatment maxillary and mandibular frontal view

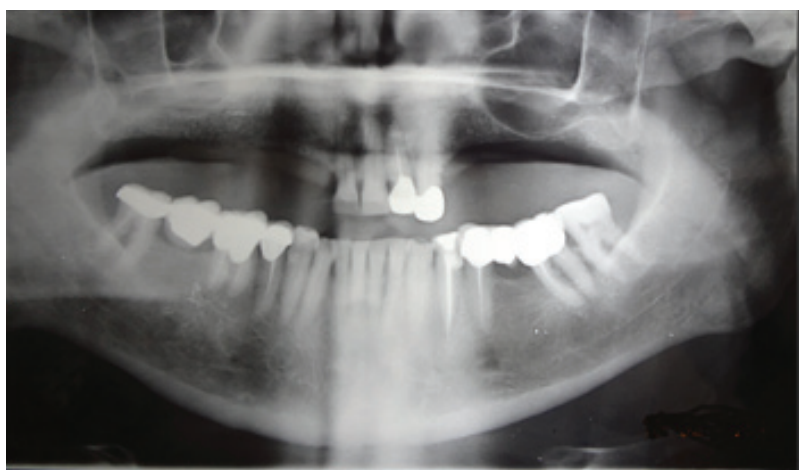

Figure 2: Panoramic radiograph examination

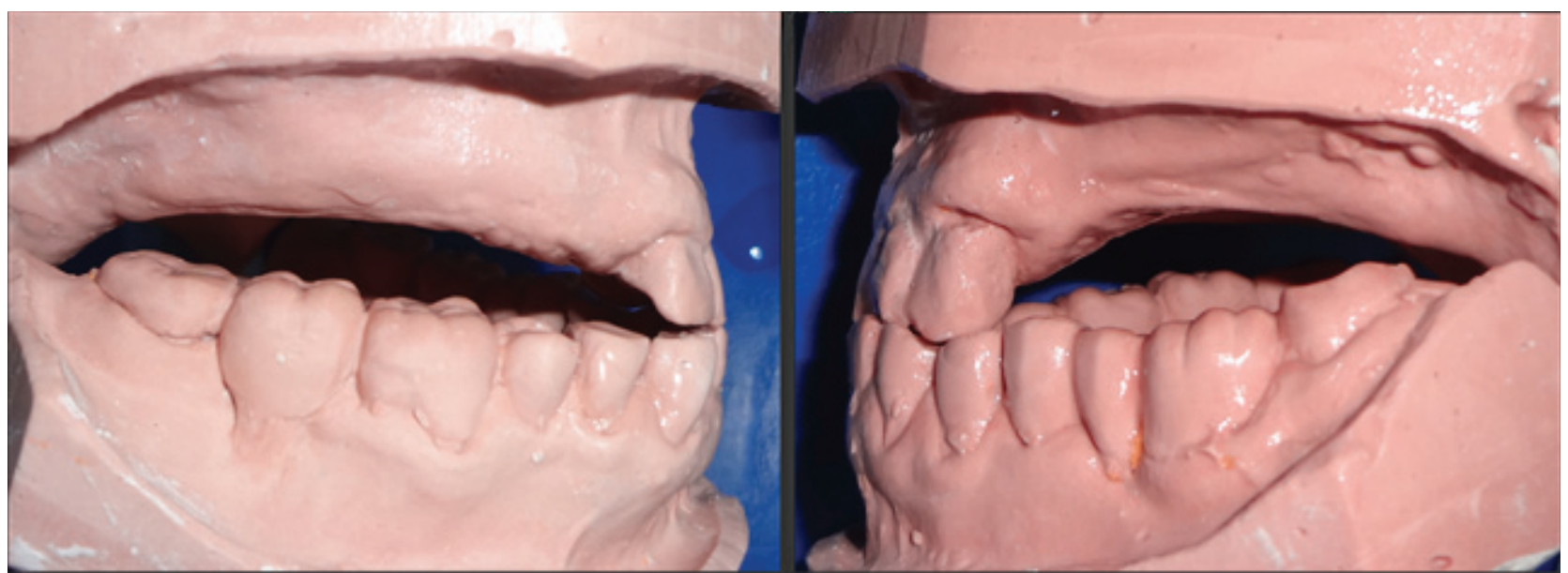

Figure 3: Analysis of diagnostic casts mounted on semi adjustable articulator 


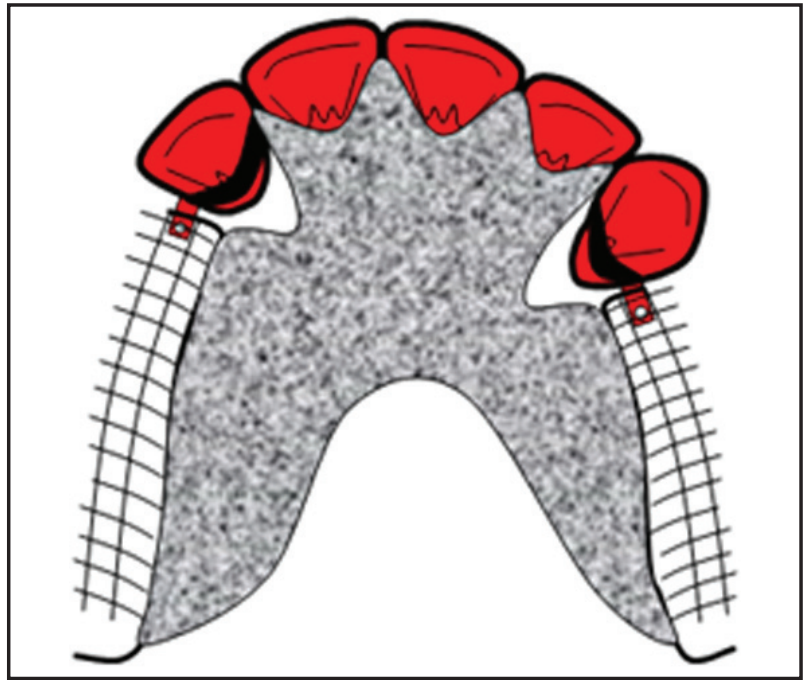

Figure 4: maxillaryprosthetic project

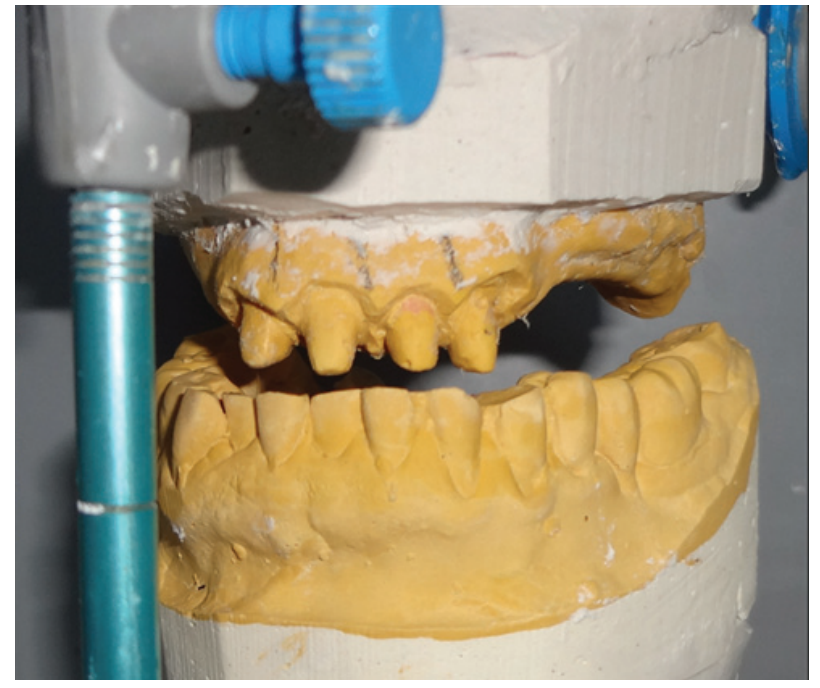

Figure 5: maxillo-mandibular occlusion record after tooth preparation

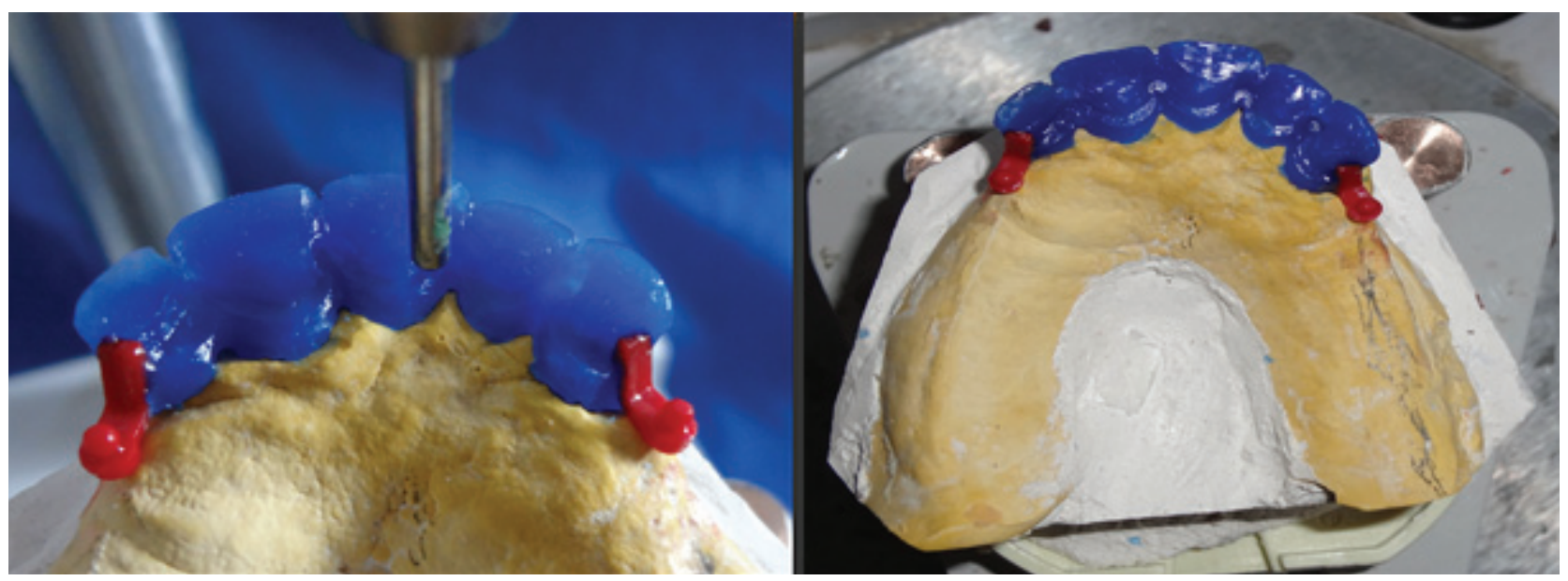

Figure $6 \& 7$ : wax pattern and attachments placement
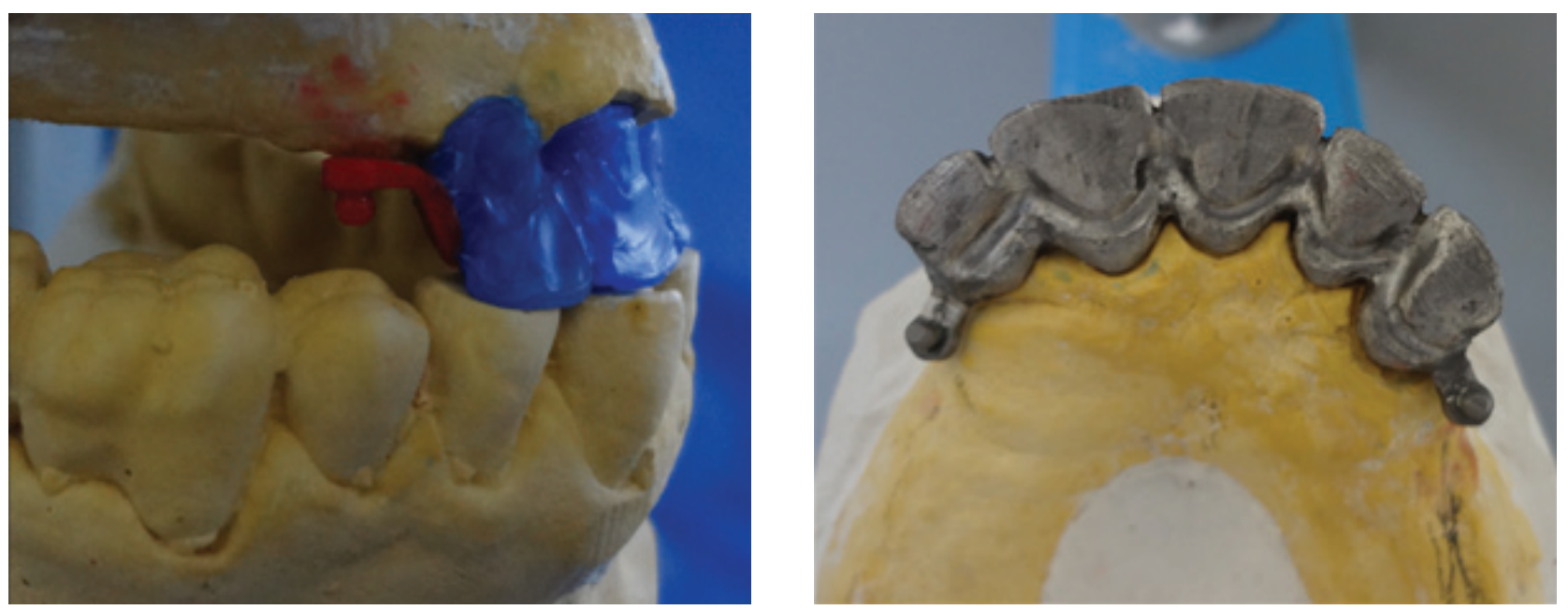

Figure $8 \& 9$ :checking the vertical prosthetic space, casting the wax pattern 




Figure 10: fixing the female part of attachment

\section{Discussion}

Distal extension partial dentures (Kennedy Class I and II) present challenges for clinicians, as these dentures are subject to vertical, horizontal and torsional forces during masticatory function, beside the permanent rotational tendency of the removable partial denture. ${ }^{7}$ Another important factor in Kenndy classe I and II is the amount of exposure of anterior tooth surfaces with lips at rest or during function when the distal extension is boarded by incisive or canine.

Treatment planning Kennedy Class I include various treatment options: the removable partial denture, the attachment-retained partial dentures and implants. ${ }^{8}$

Using single implants bilaterally at the distal extension of the denture base seems to be the ideal therapeutic option to minimize the potential for dislodgement as it converts the Kennedy classification from Class I to Class III. , $^{10}$

For the current case report, after the medical history and investigations, limited bone height is observed and bone reconstruction is counterindicated for medical consideration, besides the necessity of a resin flange to provide adequate support for facial structures. Thus, making the

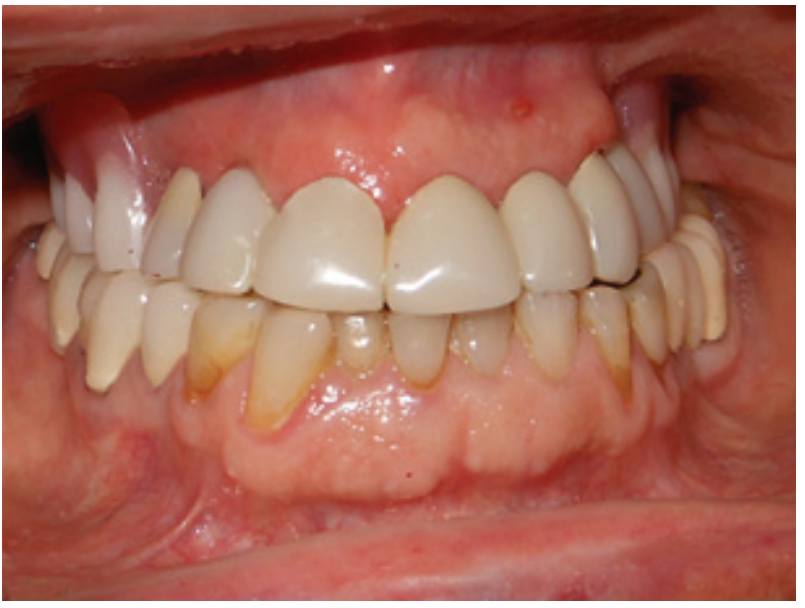

Figure 11: The final result

entire treatment complicated. However, if a traditional removable partial denture (RPD) is used, insufficient retention, unaesthetic display of direct retainers, food impaction under the distal extensions and compromised abutment teeth may induce problems.

When esthetics and retention are desired, precision-attachment partial dentures are a superior alternative to the clasped partial denture, especially in Kennedy Class I bilateral distal-extension cases.

Dr. Herman Chayes was the first reported the invention of attachment in the early 20th century. ${ }^{11}$

They are used to join the removable prosthesis to a fixed restoration. The patients found the prostheses comfortable and they satisfy with the esthetic result (no clasp), the retention and stability of the appliances. ${ }^{12}$

Studies have shown a survival rate of $83.35 \%$ for 5 years, of $67.3 \%$ up to 15 years, and of $50 \%$ when extrapolated to 20 years. $^{13,14}$

The result of Mahross and Baroudi's study for retention analysis showed that s OT cap attachment and OT strategy attachment have slight wear and retention loss because they have a resilient component systems. ${ }^{15}$ 


\section{Conclusions}

Maxillary rehabilitation using an FPD/RPD with attachments is one of the most conservative and best indicated therapeutic modalities considering the limiting bone condition and the extension of the prosthetic space. Furthermore, this treatment option provides a better esthetic appearance and improved retention and function than does a conventional clasp-retained RPD.

\section{References}

1. Chikunov I, Doan P, Vahidi F: Implantretained partial overdenture with resilient attachments. J Prosthodont 2008;17:141-148. doi: 10.1111/j.1532-849X.2007.00261.

2. Viennot S, Dalard F, Malquarti G, et al: Combination fixed and removable prostheses using a CoCr alloy: a clinical report. J Prosthet Dent 2006;96:100-103.DOI: 10.1016/j. prosdent.2006.04.013

3. Turkyilmaz I: Use of distal implants to support and increase retention of a removable partial denture: a case report. J Can Dent Assoc 2009;75:655-658.https://pubmed.ncbi.nlm.nih. gov/19900356/

4. Leupold RJ, Faraone KL: Etched castings as an adjunct to mouth preparation for removable partial dentures. J Prosthet Dent doi: 10.1016/0022-3913(85)90014-9. 1985;53:655658.

5. Renner RP: Semiprecision attachment-retained removable partial dentures. Quintessence Dent Technol 1994;17:137-144

6. Sadig W, Fahmi F: The modified swing-lock: a new approach. J Prosthet Dent 1995;74:428431doi: 10.1016/s0022-3913(05)80387-7

7. Mendes S P and al. Implants to Improve Removable Partial Denture Retention. Dent Today. 2011 Feb;30(2):118. https://pubmed. ncbi.nlm.nih.gov/21400992/
8. George E.Prosthetic Replacement Options for Restoring Kennedy Class I Bilateral Distal Extension Cases. Inside Dentistry. January 2008.Volume 4, Issue 1https://www. aegisdentalnetwork.com/id/2008/01/clinicaltreatment-options-prosthetic-replacementoptions-for-restoring-kennedy-class-i-bilateraldistal-extension-cases

9. Keltjens HM, Kayser AF, Hertel R, Battistuzzi PG. Distal extension removable partial dentures supported by implants and residual teeth: considerations and case reports. Int $\mathrm{J}$ Oral Maxillofac Implants. 1993;8(2):208-13https:// pubmed.ncbi.nlm.nih.gov/8359879/

10. Uludag B, Celik G. Technical tips for improved retention and stabilization of a unilateral removable partial denture. J Oral Implantol. 2007;33(6):344-6.doi: 10.1563/1548-1336(2007)33[344:TTFIRA]2. $\mathrm{CO} ; 2$.

11. Gupta N, Bhasin A, Gupta P, Malhotra P.Combined Prosthesis with Extracoronal Castable Precision Attachments. Case Rep Dent. 2013.DOI: $10.1155 / 2013 / 282617$

12. Hawrami G. R..PRECISION ATTACHMENT RETAINED REMOVABLE PARTIAL DENTURE. Prosthesis appliance. November 2019DOI:10.13140/RG.2.2.12182.09283

13. J. L. Bakers and R. J. Goodkind, Precision Attachment Removable Partial Dentures, Mosby, San Mateo, Calif, USA, 1981.

14. D. R. Burns and J. E. Ward, "Review of attachments for removable partial denture design:1. Classification and selection," The International Journal of Prosthodontics, vol. 3, no.1, pp. 98-102, 1990.https://pubmed.ncbi. nlm.nih.gov/2196898/

15. Mahross HZ., Baroudi K. Evaluation of Retention and Wear Behavior for Different Designs of Precision Attachments. Oral Health and Dental Management Vol. 14(No. 4):244-249. August 2015DOI:10.4172/22472452.1000819 . 